\title{
periferio
}

\section{HISTÓRIAS DE CRIANÇAS COM DEFICIÊNCIA: POR UM JORNALISMO QUE NARRA E DÁ VOZ}

\author{
Giselle Freire Borges Coelho ${ }^{1}$ \\ Faculdade Cásper Líbero
}

\section{Resumo}

Este artigo propõe discussões sobre como, por meio da compreensão de narrativas míticas, dialógicas e produtoras de conhecimento, seremos capazes de contar histórias e tecer narrativas mais humanas e ternas no exercício do jornalismo. As narrativas míticas são histórias compartilhadas por toda a humanidade na tentativa de significar e dar respostas às questões humanas mais profundas. Argumenta-se, então, como as narrativas jornalísticas, a exemplo das míticas, podem tornar visíveis questões importantes como o reconhecimento das crianças com deficiência de modo inclusivo, com o objetivo de exercer real influência em nossa sociedade, e criar uma realidade, mais justa e igualitária, baseada no princípio do respeito às diferenças. Tendo como base teórica o pensamento de Carl Jung, Joseph Campbell, Karen Armstrong, Hannah Arendt, Martin Buber e Cremilda Medina, o texto traz indicações de como cultivar a compreensão na prática do jornalismo. Tomamos, como exemplo, os textos da jornalista Eliane Brum que quebram o paradigma do jornalismo tradicional, alterando seu foco e dando voz às pessoas antes esquecidas, narrando com afeto o que é estar vivo e afirmando o protagonismo e a importância de cada ser humano. São analisadas, ainda, duas matérias da Revista Crescer sobre crianças com deficiências.

Palavras-chave: comunicação; narrativas; mito; compreensão; inclusão

\footnotetext{
1 Mestranda em Comunicação pela Faculdade Cásper Líbero, linha de pesquisa "Produtos midiáticos: jornalismo e entretenimento". Formada em Comunicação Social com habilitação em Jornalismo pela Escola de Comunicação da Universidade Federal do Rio de Janeiro - ECOUFRJ. freire.giselle@gmail.com
} 


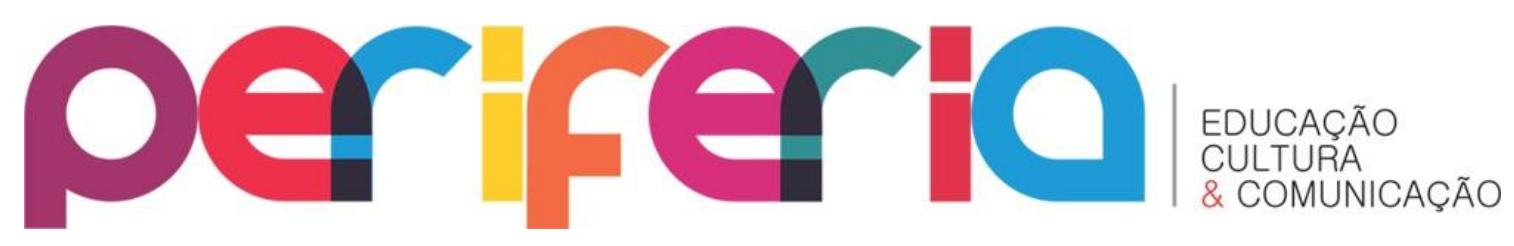

\title{
STORIES OF CHILDREN WITH DISABILITIES: FOR A JOURNALISM THAT NARRATES AND GIVES VOICE
}

\begin{abstract}
This article comes up with discussions about how, through the understanding of mythical narratives, we will be able to tell more human and affectionate stories in the exercise of journalism. Mythical narratives are stories shared by all humankind in an attempt to signify and give answers to the deepest human questions. It is argued, then, how journalistic narratives, like mythic narratives, can make visible some important issues such as the recognition of children with disabilities in an inclusive way, with the objective of have real influence in our society, and create a more fair and egalitarian reality based on the principle of respect for differences. With the theoretical basis of Carl Jung, Joseph Campbell, Karen Armstrong, Hannah Arendt, Martin Buber and Cremilda Medina, the text gives indications on how to improve understanding in the practice of journalism. We take, for example, the texts of journalist Eliane Brum that break the paradigm of traditional journalism, changing its focus and giving voice to those previously forgotten, narrating with affection what it is to be alive and affirming the protagonism and the importance of each human being. Two issues of the Crescer magazine on children with disabilities are also analyzed.
\end{abstract}

Keywords: communication; narratives; myth; understanding; inclusion 


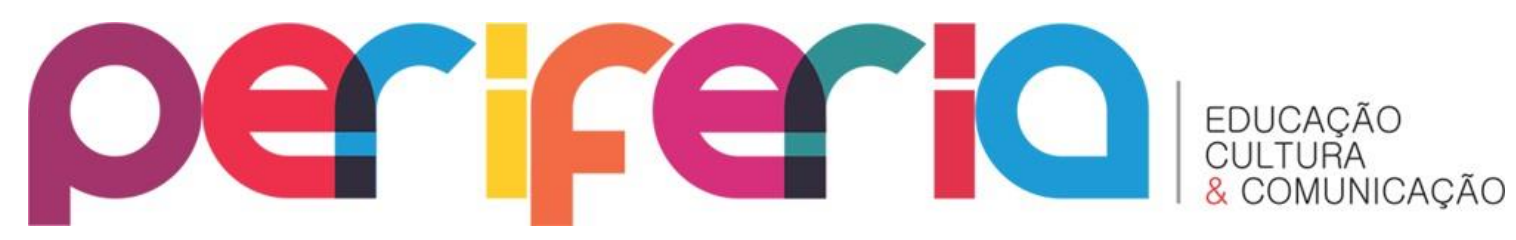

Precisamos contar histórias. É por meio de nossas histórias que significamos o mundo, as pessoas e as coisas ao nosso redor. Buscamos a compreensão para tudo o que existe, e a narrativa é um instrumento capaz de criar e dar sentido à nossa existência. Contamos histórias pois "elas representam nossas ações e situações de vida, nossa história e memória. Representam o mundo de forma coerente e compreensível. Ajudam a entender a aventura humana e organizar nossas experiências no transcurso da vida" (MOTTA, 2009, p. 2).

No entanto, esta necessidade de significar não é privilégio do homem moderno. Desde sempre, buscamos narrar e dar ordem a tudo o que nos circunda. 0 estudo dos mitos arcaicos nos aponta caminhos que levam a uma busca constante de compreender a nós mesmos, ao que fazemos aqui e para onde vamos. Segundo Karen Armstrong, "a mitologia foi, portanto, criada para nos auxiliar a lidar com as dificuldades humanas mais problemáticas" (ARMSTRONG, 2005, p.11). Os mitos são histórias compartilhadas por toda a humanidade na tentativa de significar e dar respostas às questões humanas mais profundas.

Em contrapartida, essa necessidade de respostas nos levou, a partir dos séculos XVIII e XIX, a uma negação do mito, e à fantasia de que apenas a ciência e a técnica poderiam solucionar todos os nossos problemas e levar 0 homem ao progresso: "Também as ciências modernas, tanto as da natureza quanto em sua cola as do espírito, apostaram, por pelo menos quatro séculos inteiros. Acreditaram, em vão, poder 'atingir toda a verdade'[...]" (KÜNSCH, 2014b, p.116).

Acabamos mais preocupados com os fatos e com a razão do que com a imaginação, esquecendo-nos que todos os saberes humanos são compostos por narrativas e que a razão não é a única forma de conhecimento possível. Se unirmos a imaginação à técnica poderemos criar muito mais narrativas do que apenas uma ciência que carregue o signo da explicação, pretensão de ser a única a dar todas as respostas possíveis e verdadeiras. 


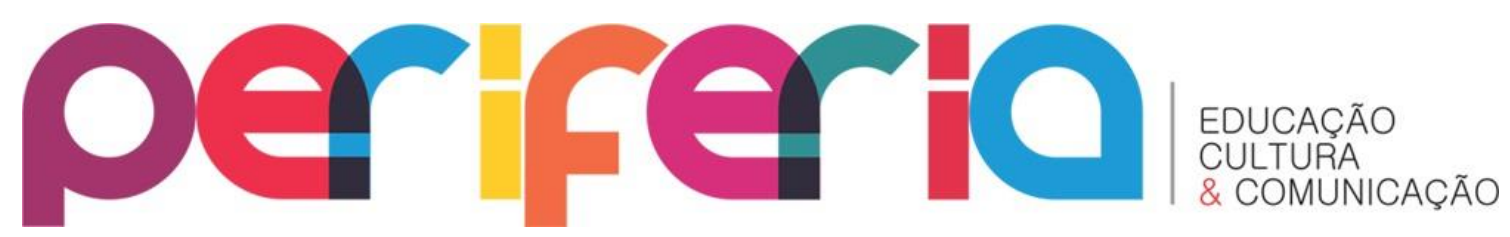

O objetivo deste artigo é levantar discussões sobre como, por meio da compreensão das narrativas míticas, dialógicas e produtoras de conhecimento, torna-se possível, no exercício do jornalismo, contar histórias e tecer narrativas mais humanas e ternas. No caso, histórias capazes de enxergar as crianças com deficiência e reconhecê-las de modo inclusivo, para que assim possamos exercer real influência em nossa sociedade.

Navegaremos na tentativa de reconhecer no jornalismo, enquanto narrativa, como um produtor de novos significados, e para longe das rotinas tecnicistas do dia a dia, "experimentar uma narrativa ao mesmo tempo complexa, afetuosa e poética" (MEDINA, 2003, p. 50).

\section{CIÊNCIA E MITO: A NECESSIDADE DA INCERTEZA}

Os séculos XVIII e XIX deixaram um legado de progressos técnicos e transformações sociais na humanidade. $\mathrm{E}$ com eles, vieram também as certezas absolutas e o cientificismo. A imaginação deu lugar à lógica do pensamento racionalista.

Hoje, o pensamento mitológico caiu em desgraça; com frequência o descartamos por irracional e indulgente. Mas a imaginação também é a faculdade que permite aos cientistas trazer novos conhecimentos à luz e criar a tecnologia que nos torna incomensuravelmente mais eficientes [...]. Tanto a mitologia quanto a ciência ampliam os horizontes do ser humano (ARMSTRONG, 2005, p.08).

O lado subjetivo da realidade foi relegado ao segundo plano, somente voltando a ter relevância na última década do século XIX, "quando a ciência positivista passou a ser criticada e a soberania da razão, condenada" (GRINBERG, 1997, p.21).

Com o resgate do outro lado, abria-se a possibilidade para o feminino e as emoções. A fantasia, a imaginação, o sonho e a linguagem do mito começavam a ser valorizados e ganhavam espaço para sua expressão. O desconhecido, assim como a 


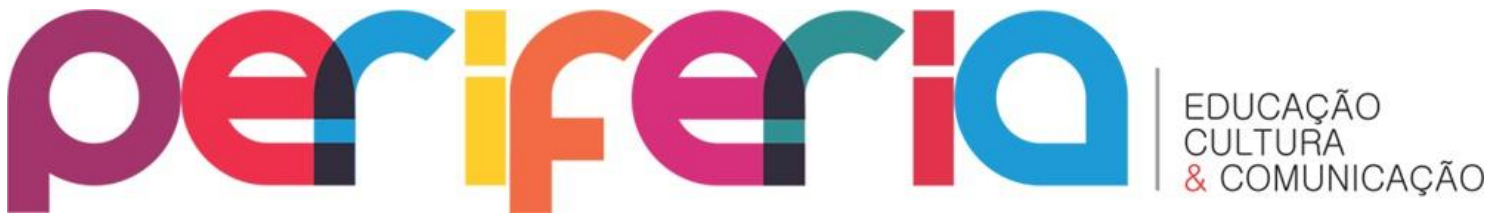

subjetividade, passavam a ser encarados como realidades em si, cheios de vida e de significados. Não era mais possível encaixar todo o mundo subjetivo em um conjunto de leis gerais e absolutas espremidas dentro de fórmulas matemáticas previsíveis (GRINBERG, 1997, p.22).

A descrição do mundo por meio da física clássica, que relata somente ser possível uma mesma resposta única e absoluta para um fenômeno, foi revista no início do século XX. Pesquisadores abriram, então, as portas para uma ciência onde o observador faz parte da experiência e pode influenciá-la intimamente.

[...] se pretendemos não ter uma visão unilateral da realidade e não nos tornar ditadores em nossa própria casa, são necessários tanto o pólo objetivo da realidade, comandado pela razão, quanto o pólo subjetivo, expresso pela linguagem mítica da fantasia, dos sonhos e da imaginação (GRINBERG, 1997, p. 23).

Nessa mesma época, Carl Jung, por meio dos estudos dos mitos, desenvolveu suas teorias sobre o inconsciente coletivo, sonhos e fantasias.

Jung (2013) nos ensinou que temos dois tipos de pensamento e que um não é inferior ao outro. Com o pensamento dirigido, lógico e voltado para a realidade, nos comunicamos. A matéria desse pensamento é a linguagem e suas expressões são a ciência e a técnica. Com o segundo tipo de pensamento podemos sonhar ou fantasiar. É um pensamento imaginativo, espontâneo, subjetivo, dirigido por motivos inconscientes e que liberta de tendências; é a força criadora da mitologia. "A origem dos mitos remonta ao primitivo contador de histórias, aos seus sonhos e às emoções que sua imaginação provocava nos ouvintes" (JUNG, 2008, p. 90).

A imaginação, os sonhos, também foram se acumulando e todo este conteúdo simbólico deu origem ao que Jung chamava de sonho coletivo, o mito. Mitos são, originalmente, revelações e projeções do inconsciente, como frases involuntárias e acontecimentos do inconsciente, como nos conta Nise da Silveira (1981), em seu livro sobre Jung: 


\section{periferio}

Os mitos condensam experiências vividas repetidamente durante milênios, experiências típicas pelas quais passaram (e ainda passam) os humanos. Por isso temas idênticos são encontrados nos lugares mais distantes e mais diversos. A partir desses materiais básicos é que sacerdotes e poetas elaboram os mitos, dando-lhes roupagens diferentes, segundo as épocas e as culturas (SILVEIRA, 1981, p. 119).

Jung (2008) baseou seu trabalho na conexão entre tendências psíquicas e a mitologia. O ser humano é como é devido a uma série de eventos e histórias coletivas que sempre precedem o surgimento das coisas. Essa herança coletiva constitui a natureza humana, não só do homem antigo, mas do homem em qualquer tempo. Todas as sociedades têm suas histórias contadas pelos mitos. Os mitos traçam nossos caminhos com narrativas escritas por símbolos. Não são verdades científicas, são verdades simbolizadas pelas vivências humanas desde o homem primitivo até o homem atual. "A mentalidade primitiva não inventa mitos, mas os vivencia. Os mitos são revelações originárias da alma pré-consciente, pronunciamentos involuntários acerca do acontecimento anímico inconsciente e nada menos do que alegorias de processos físicos" (JUNG, 2000, p. 261).

A modernidade ocidental, baseada no logos, na razão, nos treinou no espírito científico e pragmático da eficiência. "Mas o logos nunca foi capaz de dar aos seres humanos a sensação de importância que parecem exigir. O mito providenciara estrutura e significado à vida [...]" (ARMSTRONG, 2005, p.103).

\section{MITO, ONDE NOSSAS HISTÓRIAS SE ENCONTRAM}

Paralelamente às teorias de Jung, Joseph Campbell realizava seus estudos baseando-os na hipótese de que todas histórias estão ligadas por uma ideia central comum. Assim, desde os mitos antigos, passando pelas fábulas e pelos contos de fadas até os mais recentes sucessos do cinema, os seres humanos continuam contando e recontando as mesmas histórias. Essa história central e comum a todas as outras é chamada por Campbell de Monomito, e 


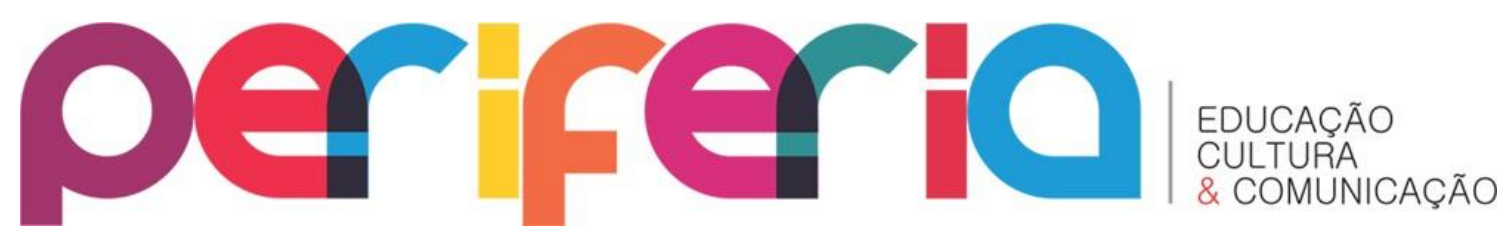

tem servido de base para profissionais que estudam e se dedicam às diversas formas do contar histórias, desde psicólogos até escritores e roteiristas.

O sonho é o mito personalizado e o mito é o sonho despersonalizado; o mito e o sonho simbolizam, da mesma maneira, a dinâmica da psique. Mas, nos sonhos, as formas são destorcidas pelos problemas particulares do sonhador, ao passo que, nos mitos os problemas e soluções apresentados são válidos para toda a humanidade (CAMPBELL, 2007, p. 28).

A partir desta hipótese, Campbell analisa as etapas do Monomito, a Jornada do Herói, cuja primeira tarefa é retirar-se do mundo e iniciar uma jornada pelo nosso inconsciente, a fim de esclarecer e eliminar as dificuldades em nossas vidas. "O herói, por conseguinte, é o homem ou mulher que conseguiu vencer suas limitações históricas pessoais e locais e alcançou formas normalmente válidas, humanas" (CAMPBELL, 2007, p. 28). A segunda tarefa é retornar ao nosso meio, renovado pelo entendimento para ensinar a lição de vida que apreendeu. A aventura do herói é, antes de qualquer coisa, uma tarefa de autoconhecimento.

Além disso, nem sequer teremos que correr os riscos da aventura sozinhos; pois os heróis de todos os tempos nos precederam; o labirinto é totalmente conhecido. Temos apenas que seguir $o$ fio da trilha do herói. $E$ ali onde pensávamos encontrar uma abominação, encontraremos uma divindade; [...] e onde pensávamos estar sozinhos, estaremos com o mundo inteiro (CAMPBELL, 2007, p.32).

É por meio destas narrativas que construímos nossa identidade. 0 mito, narrativa coletiva e matriz para os textos de nossas culturas, nos traz o conhecimento ancestral e nos une como seres humanos.

É a partir desses estudos que se torna possível afirmar que precisamos contar histórias. Não apenas para termos registros do passado, mas, principalmente, para tentarmos entender o presente e a nós mesmos. "Criar, representar, contar histórias não são um luxo reservado a poucos 'eleitos' (os artistas, os publicitários, os dotados etc.); é sim, [...] uma atividade que 


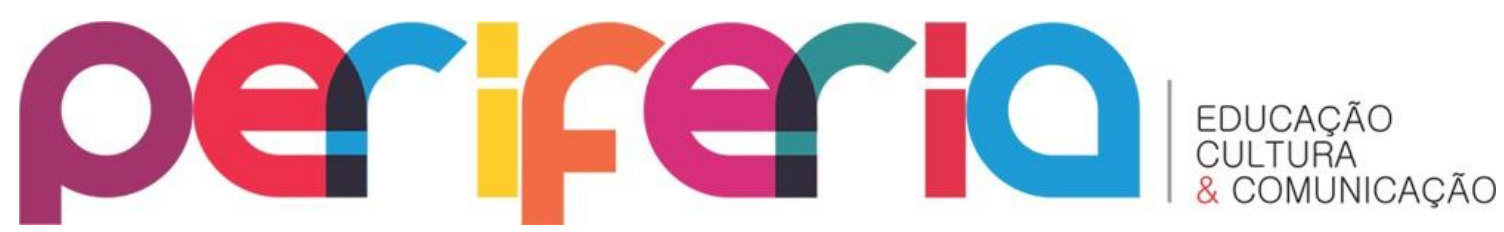

nasce com o próprio homem, uma necessidade surgida de uma luta básica pela sobrevivência. (CONTRERA, 2003, p. 99).

Para além de dar sentido à vida, Campbell nos aponta uma necessidade ainda maior de experienciar o estar vivo. Não há humanidade sem história, não existimos se não narramos. As histórias talvez sejam a principal maneira de tocar a experiência de estar vivo.

Dizem que o que todos procuramos é um sentido para a vida. Não penso que seja assim. Penso que o que estamos procurando é uma experiência de estar vivos, de modo que nossas experiências de vida, no plano puramente físico, tenham ressonância no interior de nosso ser e de nossa realidade mais íntima, de modo que realmente sintamos o enlevo de estar vivos. É disso que se trata, afinal, e é o que essas pistas nos ajudam a procurar, dentro de nós mesmos (CAMPBELL, 1990, p. 16).

\section{SOB O SIGNO DA COMPREENSÃO}

As narrativas mitológicas nos guiam pelo signo da compreensão. Reconhecem nossa capacidade de enxergar vários pontos de vista, várias possibilidades de criar o mundo sem a necessidade de que tudo seja explicado.

O Signo da Compreensão, compreensivamente, não condena nem renuncia a toda explicação. Inclusive porque sem explicações não se vive. Rejeita, isso sim - aliás, como um tributo de respeito ao melhor de todo esforço explicativo -, a vã ideia de que tudo se explica, de que os sentidos se fecham, de que o mundo é, de que a vida é. Nas sendas da compreensão, há lugar também para o inefável, o mistério, as entrelinhas e as dobras que ajudam a tecer e a entretecer os sentidos reais e presumidos das coisas. Há um lugar de honra reservado ao princípio da incerteza (KÜNSCH, 2010, p. 20-21).

Várias reportagens têm descrições e enfoques que não precisaríamos saber ou explicar. A profundidade que importa e que nos faz pessoas 


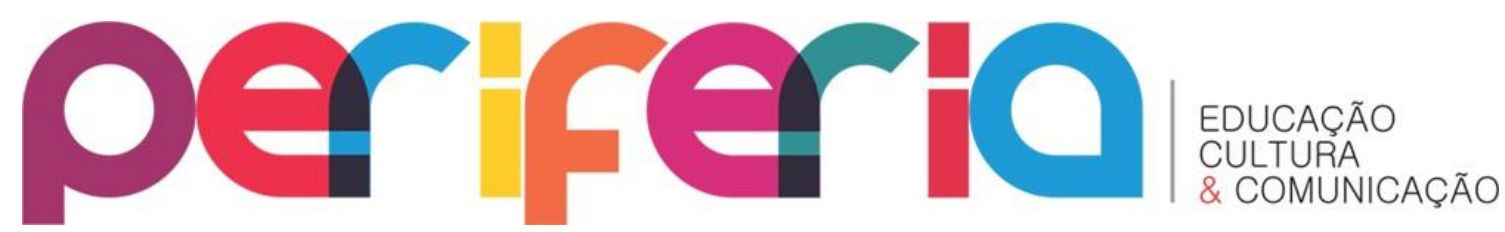

melhores, muitas vezes é calada. Por isso, talvez com a ajuda da compreensão, possamos efetivamente produzir um conhecimento profundo. “A compreensão faz conhecer. Ela produz conhecimento sobre as pessoas, a sociedade e a natureza, assumindo, desse modo, legitimamente, o estatuto de uma verdadeira episteme”. (KÜNSCH, 2014, p.10).

As narrativas construídas a partir do signo da compreensão, além de humanizarem as relações humanas, conduzem os jornalistas e leitores em direção a um conhecimento mais profundo e real. Nos mostra a necessidade de olhar verdadeiramente o Outro.

Ele é o outro, o que não pertence, o diferente, e essa sua diferença pode ser discursivamente trabalhada em termos mais ou menos visíveis - narrar o outro é classificar o outro e a si mesmo nessa relação [...]. Compreender o outro, nesse sentido, é tentar ver nele a mesma complexidade que reivindicamos para nós, e suportar a mesma falta de lógica, de coerência e de sentido da qual damos mostra. (MARTINO, 2014 p.19).

A compreensão elimina barreiras e cria pontes para que possamos estar confortáveis com quem estamos dialogando. Quanto mais pontes criarmos, mais nos colocamos no lugar do Outro. Este lugar onde, como nos fala Vilém Flusser (2007), podemos captar a alteração que é processada em mim durante os diálogos com as pessoas. Segundo Flusser, é no diálogo, que podemos criar uma nova informação, uma nova visão, um novo olhar.

Do ponto de vista da “informação”, há diferença fundamental entre diálogo e discurso, não suficientemente apreciada pelos estudos em curso. 0 discurso é processo pelo qual informações existentes são transmitidas por emissores, em posse de tais informações para receptores que "devem ser" informados. 0 diálogo, pelo contrário, é processo pelo qual vários detentores de informações parciais ou duvidosas (ou, em todo caso, duvidadas) trocam tais informações entre si, a fim de alcançar síntese que possa ser considerada "informação nova" (FLUSSER, 2007, p. 115). 


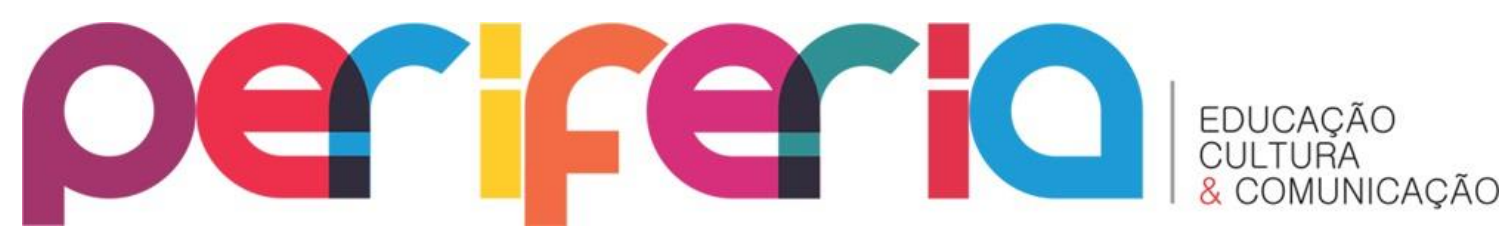

Para que este diálogo possa realmente acontecer, e essa nova informação brotar, é preciso ainda entender a distância certa para se compreender e falar sobre algo. Para Arendt (2008), não é possível que haja compreensão sem que o contato com os que queremos compreender aconteça na medida certa. E esse espaço precisa ser preenchido pela imaginação. Não aquela imaginação dos sonhos ou da fantasia, mas a imaginação como a “essência” ou a "natureza" de alguma coisa. Para a autora, imaginar é ver a essência do Outro.

Somente a imaginação permite que enxerguemos as coisas em sua perspectiva adequada, que tenhamos forças suficientes para afastar o que está demasiado próximo, a fim de conseguir ver e compreender sem distorções nem preconceitos, que tenhamos generosidade suficiente para transpor abismos de lonjuras, a fim de conseguir ver e compreender, como se fosse uma questão pessoal nossa, tudo o que está demasiado distante de nós. Esse distanciamento de algumas coisas e avizinhamento de outras faz parte do diálogo da compreensão, pois, para suas finalidades, a experiência direta envolve contato próximo demais e o mero conhecimento ergue barreiras artificiais (ARENDT, 2008, p. 346).

Tal imaginação, esse novo olhar, ressignifica o que vemos, nos faz olhar com os olhos do Outro e cria vínculos. É necessário ter a imaginação para além de se colocar no lugar do Outro, ser o Outro, sem ensinamentos nem superioridade.

Quando o homem diz Eu, ele quer dizer um dos dois. O Eu ao qual se refere está presente quando ele diz Eu. Do mesmo modo quando ele profere Tu ou Isso, o Eu de uma ou outra palavra-princípio está presente. Ser Eu, ou proferir a palavra Eu são uma só e mesma coisa. Proferir Eu ou proferir uma das palavras-princípio são uma ou mesma coisa. Aquele que profere uma palavra-princípio penetra nela e nela permanece (BUBER, 2004, p. 51). 


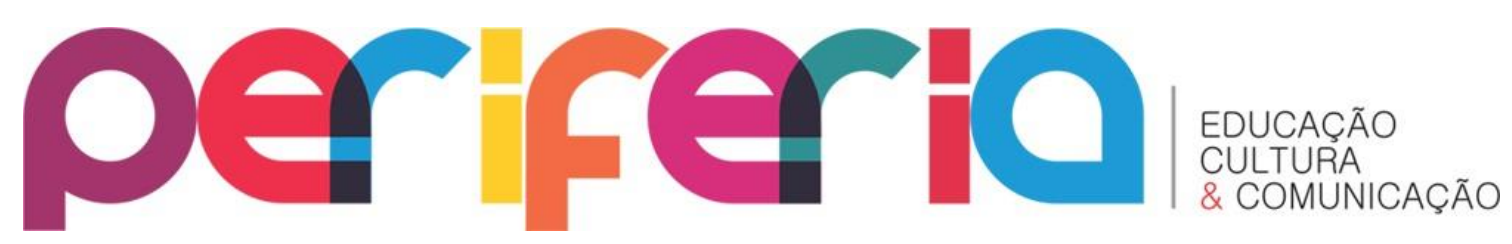

Esse nível de engajamento nos diálogos propostos por Buber, de permanecer no Outro, é o mesmo sobre o qual nos fala Flusser (2007), e é tão transformador que, para ele, conhecer uma pessoa é se perder nela.

Cremilda Medina nos aponta caminhos de compreensão e dialogia na prática da interação social no jornalismo. "Somos humildes aprendizes do diálogo possível (...). O repórter, nestas circunstâncias, precisa do silêncio subjetivo, dos sinais dos cinco sentidos e da despoluição da consciência para a escuta da intuição criadora" (MEDINA, 2008, p.67).

E para que possamos entrar de forma definitiva no signo da compreensão, precisamos remover nossas armaduras, as carcaças com que enfrentamos o mundo sempre tentando nos proteger. É preciso nos sensibilizarmos e abrirmos nossos corações. Retirar as carcaças também significa recuperarmos a visão. Não o simples enxergar, mas o tempo do olhar, o tempo de se perder na pessoa com que se dialoga, novamente trazendo as ideias de Flusser (2007) sobre o olhar. Precisamos ter a perspectiva adequada e olhar sem preconceito.

\section{NARRATIVAS QUE ENXERGAM E DÃO VOZ}

As narrativas mitológicas nos aproximam de nossos semelhantes, nos tornam iguais e nos afetam, ou como Cremilda Medina (2006) nos ensina, nos faz "afetos a". Este afeto nos sensibiliza ao Outro.

Precisamos de mitos que nos ajudem a nos identificar com
nossos semelhantes, e não apenas com que pertence a nossa
tribo étnica, nacional ou ideológica. Precisamos de mitos que
nos ajudem a valorizar a importância da compaixão, que nem
sempre é considerada suficientemente produtiva ou eficiente
em nosso mundo racional pragmático (ARMSTRONG, 2005, p.
115).

Assim como as narrativas míticas, as narrativas jornalísticas podem ser um caminho para exercermos nossos afetos e também nos deixarmos afetar 


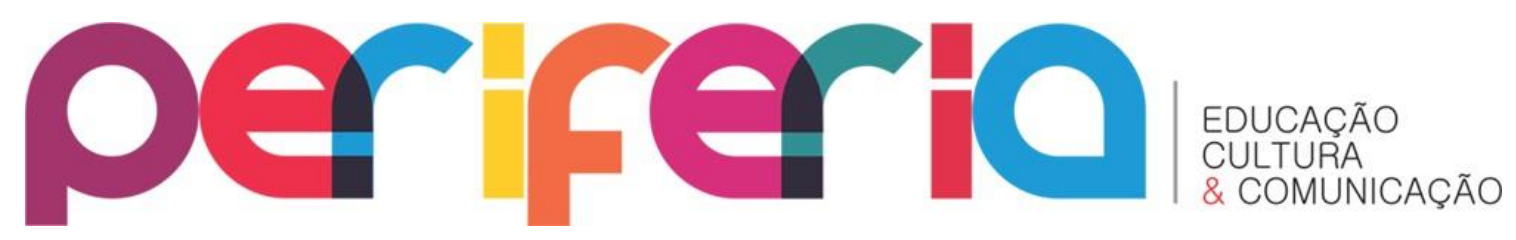

pelos outros. 0 que Karen Armstrong nos fala sobre o romance também pode ser aplicado ao jornalismo: "Um romance, como um mito, nos ensina a ver o mundo de modo diferente; ele nos diz como olhar para dentro de nossos corações e ver o mundo de uma perspectiva que vai além de nosso interesse pessoal" (ARMSTRONG, 2005, p.124).

Um exemplo de narrativa que nasce da experiência de um novo olhar, de um olhar profundo, que enxerga, é o trabalho da jornalista gaúcha Eliane Brum.

O olhar, para Eliane Brum, significa "sentir o cheiro, tocar as diferentes tessituras, perceber os gestos, as hesitações, os detalhes, apreender as outras expressões do que somos. Metade (talvez menos) de uma reportagem é o dito, a outra metade o percebido" (BRUM, 2006, p.107). Assim, Brum nega, em seus textos, a possibilidade de se deixar levar por obstáculos e atrofias. "Olfato, paladar e tato foram exilados do universo da objetivação, indesejada das subjetividades em processo de relação" (MEDINA, 2003, p. 58).

As crônicas-reportagens publicadas por Eliane Brum no Jornal Zero Hora, quebraram o paradigma do jornalismo tradicional, alterando seu foco e dando voz às pessoas antes esquecidas, narrando com afeto o que é estar vivo; afirmando o protagonismo e a importância sublime de cada ser humano.

Suas crônicas de pessoas reais em situações comuns foram editadas em um livro com o mesmo título de sua coluna que, por quase um ano, somaram 46 histórias: $A$ vida que ninguém vê (2006). Durante quase um ano foi desafiada a escrever sobre a gente comum. "Das desimportantes. O oposto, portanto, do jornalismo clássico" (BRUM, 2006, p. 187). Na coletânea, narrou "os dramas de anônimos como os épicos que são" (idem, 2006, p. 187), para assim, "estimular um olhar que rompesse com o vício e o automatismo de se enxergar apenas a imagem dada, o que era do senso comum, o que fazia com que se acreditasse que a minha vida, a sua vida, fossem bestas" (ibidem, 2006, p. 187). 


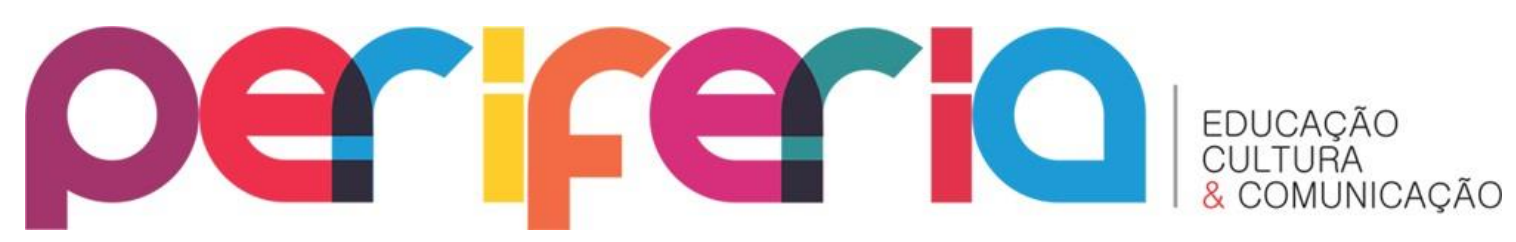

A hipótese era a de que nosso olhar fosse sendo cegado, confundido por uma espécie de catarata, causada por camadas de rotinas, decepções e aniquilamentos, que nos impedisse de ver. Vemos o que todos veem e vemos o que nos programaram para ver. Era, com toda pretensão que a vida merece uma proposta de insurgência. Porque nada é mais transformador do que nos percebemos extraordinários - e não ordinários como toda miopia do mundo nos leva a crer (BRUM, 2006, p. 129).

Figura 1: Leandro Siqueira

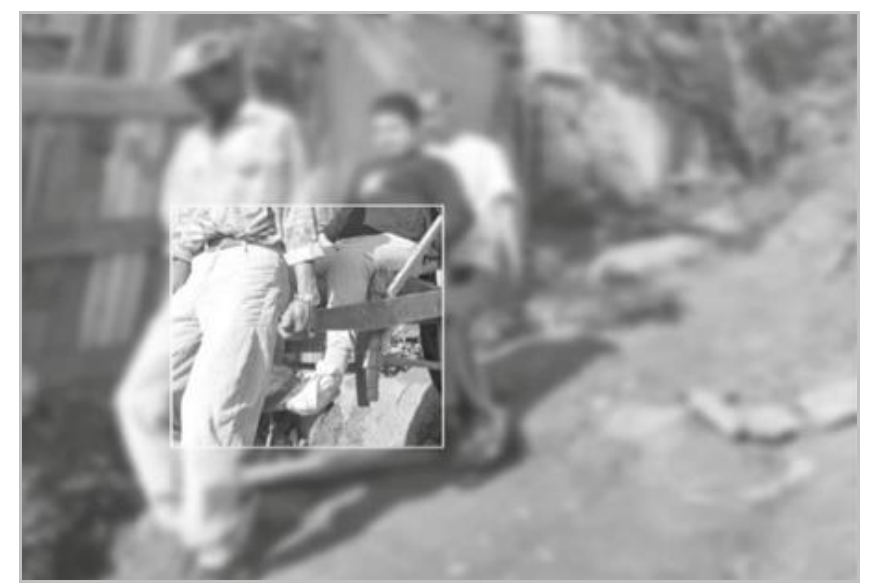

Fonte: BRUM, 2006, p. 45

Uma das histórias deste livro é protagonizada por Leandro Siqueira do Santos. Brum (2006) nos conta a história deste menino, cuja tragédia era ter nascido no alto do Morro da Polícia, favela em Porto Alegre com vista para o Ria Guaíba. Ele sofreu um acidente e, por falta de recursos, ficou sem os movimentos das pernas. História simples, como tantas outras, mas nunca simplória; a maneira como a história é contada nos afeta, nos acaricia e nos torna mais humanos:

0 drama do menino é que nasceu duas vezes. Nos primeiros 12 anos descia a cidade vertical dos trambolhões de criança, resvalando pelos barracos, rindo das pedras. Espantando a fome que assombrava a família com aquela inocência que protege a infância. Suspirando por um videogame que jamais chegaria no Natal, mas mesmo assim sonhando como só os meninos são capazes. Numa das incursões à planície, aconteceu. Nem viu o carro, não viu mais nada. Despertou cinco meses depois. Acordou para o horror. Tinha as pernas 


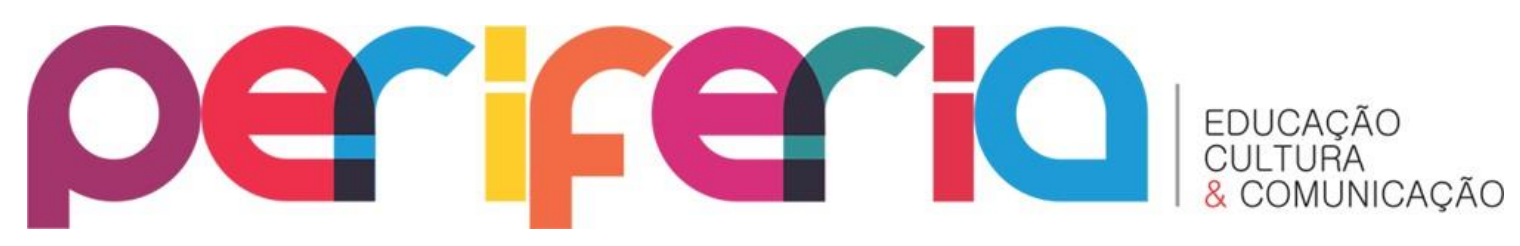

retorcidas, as mãos em garra. O menino renasceu. Como prisioneiro [...]. Quando os doutores disseram que nada mais poderiam fazer por ele, o pai arranjou uma porta velha, bichada, e sobre ela deitou o filho. Com a ajuda de parentes, dos vizinhos, do povo de cima, carregou-o até o alto de seu destino. Pela primeira vez o menino decifrou o precipício de sua vida. Pela primeira vez sentiu medo do barranco, das pedras, das cicatrizes escalavradas na terra. 0 menino percebeu naquele exato momento que havia nascido com todas as pontes dinamitadas. Quando compreendeu, começou a envelhecer. Até a voz mudou. 0 menino é desde então um prisioneiro no alto da torre na cidade. Suas pernas eram as únicas asas que tinha para voar sobre o fosso entre os dois mundos. Tão perto do céu, estava no inferno. Para os meninos de pernas assassinadas do alto, de nada serve uma cadeira de rodas [...]. Quando se mergulha no coma, o corpo dorme. Os membros, as articulações desmaiam como se perdessem a vida. Para que não se cristalizem no lugar errado, é preciso que um fisioterapeuta movimente os pés, as mãos, dia após dia. Não fizeram com o menino do alto. Selaram seu destino com a displicência com que a planície trata a cidade de cima. Não foi o acidente que roubou a liberdade do menino. Não foi o traumatismo craniano que retorceu seus pés. Foi crime (BRUM, 2006, p. 46).

Medina nos ajuda a compreender como Brum ao desejar contar a história social da atualidade, se assina, se mostra por meio de seu texto como ser humano com personalidade, criando uma marca mediadora que articula todas as histórias que conta. E, cada vez mais, os jornalistas estão se voltando para a produção de significado que para a técnica:

\begin{abstract}
Há, sim, uma insatisfação latente nos profissionais mais sensíveis diante das rotinas técnicas que comandam a produção de significados nas empresas, instituições e grupos organizados das sociedades contemporâneas. Da comunicação sindical à grande imprensa [...] deixa os consumidores, fruidores ou parceiros do caos contemporâneo, frustrados com o universo simbólico tal qual o organizam as coberturas jornalísticas (MEDINA, 2003, p. 48).
\end{abstract}

Em contrapartida, nos deparamos constantemente com o que Medina (2003) chama de metodologia explicativa. A atitude pragmática de ir ao 


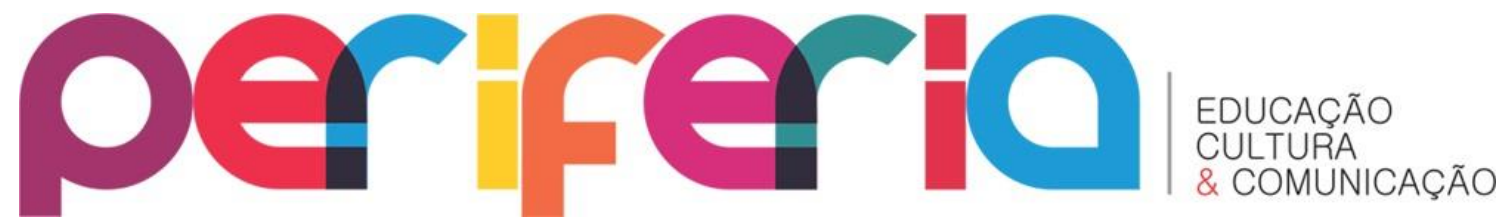

encontro dos afetos e simpatias da compreensão ainda são um desafio a ser vencido.

Narrativas que somente explicam, como a que fala sobre Danilo, na Revista Crescer (Fig.2), são um exemplo. No primeiro parágrafo é feita uma tentativa de explicar Danilo e não de contar sua história, não traz o contexto adequado e não compreende Danilo como ser humano.

Danilo, hoje com 17 anos, nasceu de 34 semanas, aparentemente saudável. Depois de três dias em casa, uma icterícia não diagnosticada tomou proporções gravíssimas: ele parou de mamar e de evacuar. Um quadro de desidratação severa se instalou e levou a uma paralisia cerebral, cujos efeitos nem Fernanda nem seu marido, o médico e professor Ubirajara Ferreira, 60, poderiam prever (SALEH, 2016, p.70).

Figura 2: Trecho da reportagem "Provas de amor"

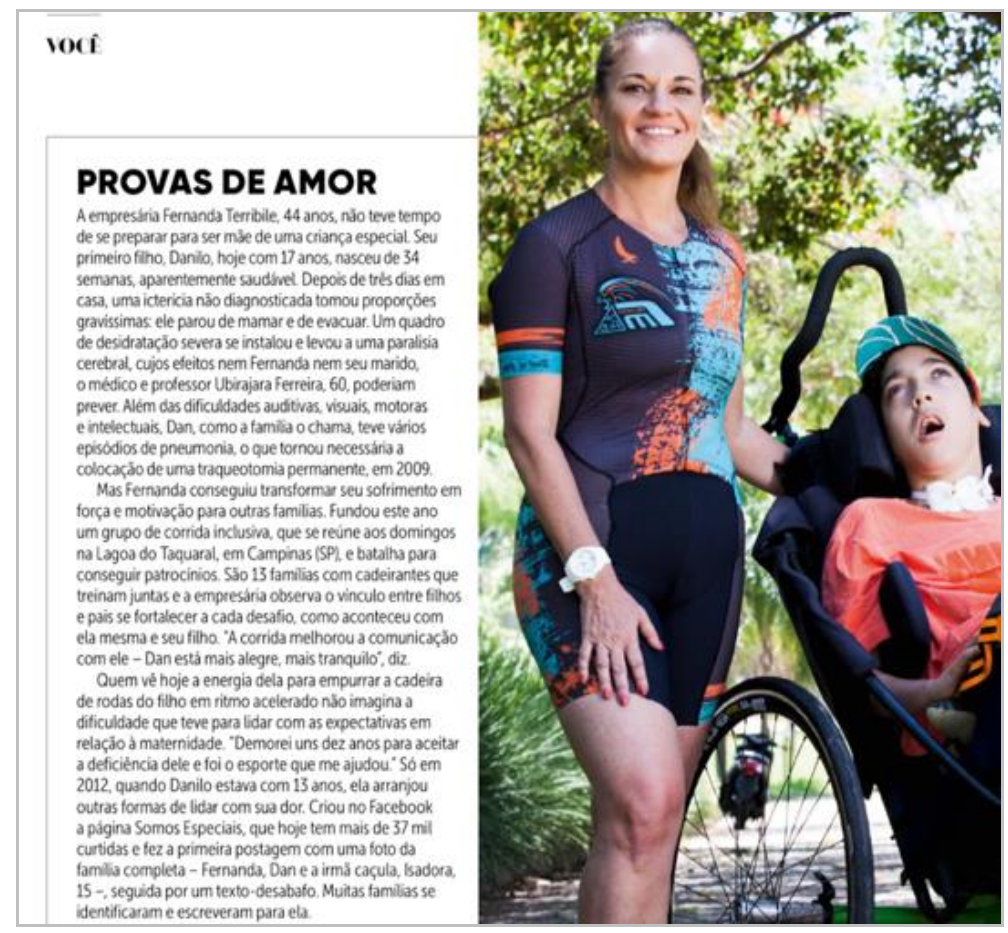

Fonte: Revista Crescer, $n^{\circ} 277$ p. 70

A reportagem sobre Danilo e sua mãe (Fig. 2) não dá espaço ao que Medina (2003) chama de insight criativo, que encontramos nos textos de Brum: 


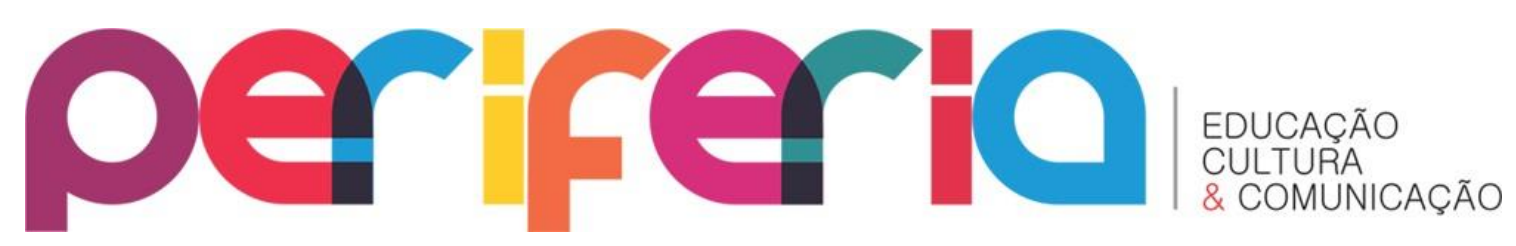

A razão treinada para resultados imediatos perde a força do afeto e não dá margem a um insight criativo. No fundo, essa é a marca de autora que se aspira: contar sua história ou a história coletiva de forma sutil e complexa, afetuosamente comunicativa e iluminando no caos alguma esperança do ato emancipatório (MEDINA, 2003, p. 49).

As reportagens de Eliane Brum contêm palavras que curam, que dão sentido às pessoas por ela perfiladas.

A atitude hipocrática de reconhecer o direito sagrado da pessoa à palavra revela uma das percepções mais inteligentes de como se processa, no concreto da vida, aquilo que, com muitos autores, podemos chamar de o poder terapêutico da palavra, da fala ou, mais propriamente, da narrativa. Temos, nesse modo de ver as coisas, magistralmente apresentada, uma verdadeira teoria do conhecimento, fundada na velha e boa arte de contar histórias, a arte da narrativa (KÜNSCH, 2014, p.53).

Outra reportagem da Revista Crescer (Fig. 3) informa sobre o novo livro de Marcos Mion, apresentador de TV, que tem um filho com Transtorno do Espectro Autista. No momento em que a reportagem fala sobre a descoberta da doença do Romeo, são usadas as seguintes palavras: "Apesar deste momento marcante, a primeira vez que Mion falou publicamente do filho foi há quase 3 anos, em janeiro de 2014, quando anunciou que Romeo fazia parte do transtorno [...]" (PONTES, 2016, p.56).

"Fazer parte do transtorno" apesar de gramaticalmente correto, não é exatamente a melhor maneira de se referir à criança. Pode ser duplamente interpretado como sendo parte do transtorno que é esta doença para os pais, ou que ele próprio é um transtorno para os pais. Este tipo de menção foi descrita por Medina como: "Uma visão funcionalista empobrecida das mediações sociais e que submete o jornalista a uma competência exclusivamente técnica, quase restrita à gramática linguística, no sentido do texto legível" (MEDINA, 2003, p. 55). 


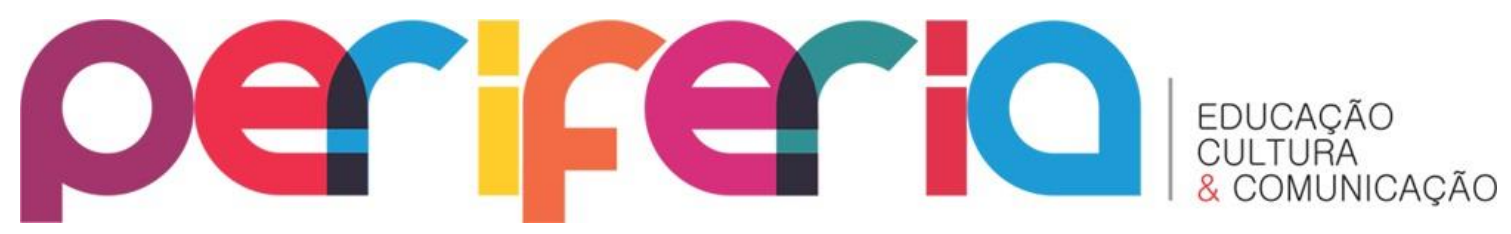

Pode parecer um simples caso de palavra mal-empregada, mas podemos considerar sintomático pelo modo persistente com que estas narrativas aparecem no jornalismo de um modo geral.

Figura 3: Trecho da reportagem "Anjo Azul”

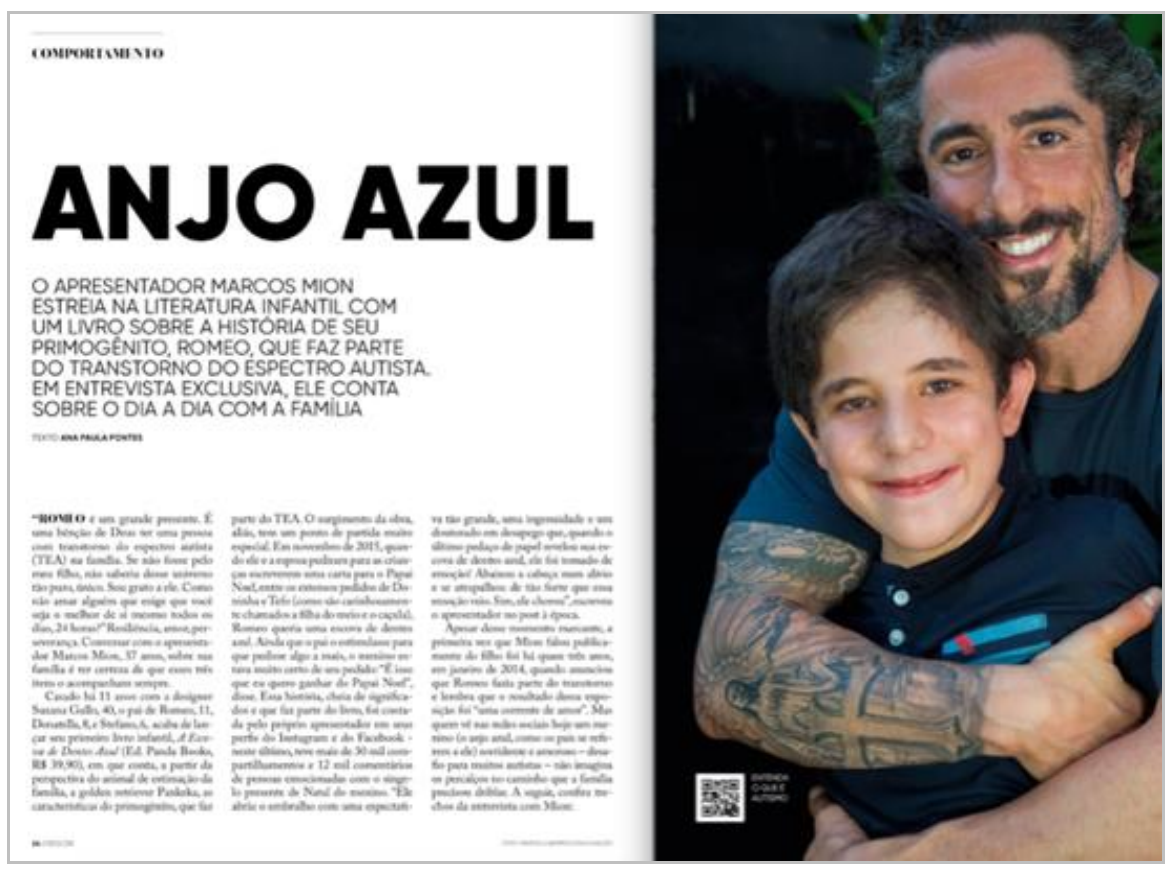

Fonte: Revista Crescer, $\mathrm{n}^{\circ} 277$ p. 56

Esse tipo de narrativa jornalística nos remete ao Signo da Explicação e não ao Signo da Compreensão "[que] se adequa muito melhor ao à complexidade do mundo do que a explicação. A compreensão dialoga. Ao contrário, o dogma expressa o ato autoritário” (KÜNSCH, 2014, p. 63). Quando as narrativas jornalísticas têm como foco a explicação pela explicação, apenas para permanecer em seu princípio de que nada pode deixar de ser nomeado, conceituado e inferido, perdem a oportunidade de imprimir um olhar compreensivo e dialógico.

[...] a racionalidade analítica é pobremente informada e daí, em lugar de argumentos elaborados, complexos, ocorrem conceitos dogmáticos, afloram preconceitos ideológicos; o fechamento numa razão reducionista impede a emoção 


\section{periferio}

solidária que capta os movimentos do outro (MEDINA, 2003, p. $50)$.

\section{REFLEXÕES FINAIS}

As narrativas mitológicas nos transportam para nossa casa, nos mostram como ser pessoas melhores, mais humanas e "[...] nos ensina[m] a compaixão, a capacidade de 'sentir com' outros. E, como a mitologia, um romance importante é fator de transformação. Se permitirmos, ele nos modificará para sempre" (ARMSTRONG, 2005, p.124).

Seria de imensa importância que as narrativas jornalísticas, assim como a mitologia, pudessem influenciar e transformar a sociedade e cada um de nós, sensibilizando a todos e se comprometendo com o enfoque constante na dignidade do ser humano.

Quando falamos, nesse texto, em cultivar o espírito compreensivo na prática do jornalismo, falamos em reverter do jornalismo o que Cremilda Medina chama de forma "desumanizada, preconceituosa e estática, a narrativa predominante exibe, de forma sintomática, as crises da cultura e da escolaridade nos marcos da modernidade" (MEDINA, 2003, p. 51).

Se a compreensão nos auxilia na criação de um mapa, cada jornalista poderá traçar seu caminho. Não precisamos virar repetidores e ter respostas prontas para tudo como se tudo tivesse realmente uma resposta, um certo e um errado. Vivemos na era da incerteza, e somos todos estranhos em um mundo estranho, como nos lembra Hannah Arendt (2008). "Olhar dá medo porque é risco. Se estivermos realmente decididos a enxergar não sabemos o que vamos ver" (BRUM, 2006, p. 134). Mas a tentativa da compreensão nos faz abertos a este mundo, nossa casa. A tentativa de compreensão das diferenças, da singularidade nos torna humanos, vivos:

Compreender é, por sua vez, uma tarefa interminável, que não produz resultados finais. Compreender é a tarefa especificamente humana de estar vivo, uma vez que todo ser humano precisa reconciliar-se com o mundo no qual surgiu 


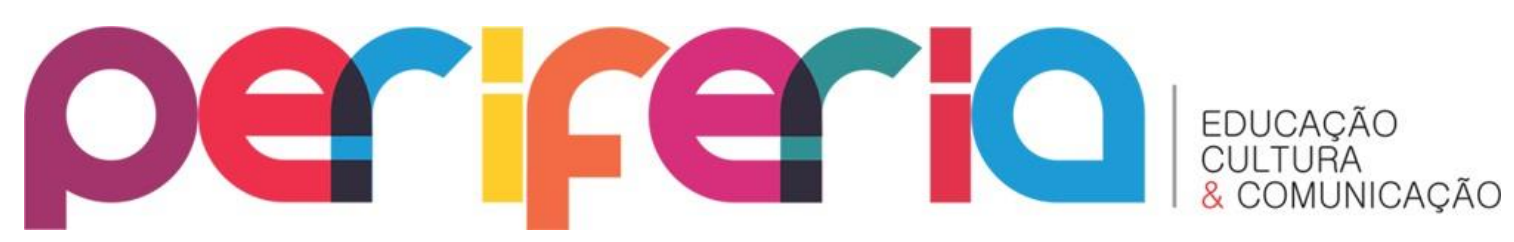

como estranho e sempre permanecerá sendo um estranho, em sua inconfundível singularidade (ARENDT, 2008, p.331).

A unidade exclui o diverso. O universal e absoluto não nos deixa ver o Outro. Afundados numa postura individualista e efêmera, como descobrir e compreender o Outro, o diverso, o diferente?

As narrativas jornalísticas compreensivas, aquelas sem necessidades de explicações em demasia e em busca de um verdadeiro encontro com o Outro, talvez sejam capazes de influenciar a sociedade para uma realidade justa e igualitária, com o princípio do respeito a qualquer tipo de diferença, e acolhendo o Outro como parte de si mesmo.

\section{REFERÊNCIAS}

ARENDT, Hannah. Compreender: formação, exílio e totalitarismos. São Paulo: Cia. das Letras, 2008.

ARMSTRONG, Karen. Breve história do mito. São Paulo: Companhia das Letras, 2005.

BRUM, Eliane. A vida que ninguém vê. Porto Alegre: Arquipélago Editorial, 2006.

BUBER, Martin. Eu e tu. São Paulo: Centauro, 2004.

CAMPBELL, Joseph. O poder do mito. São Paulo: Palas Athena, 1990.

O herói de mil faces. São Paulo: Pensamento, 2007.

CONTRERA, Malena; HATTORI, Osvaldo Takaoki (Orgs.). Publicidade e Cia. São Paulo: Pioneira Thomson Learning, 2003.

FLUSSER, Vilém. Bodenlos: uma autobiografia filosófica. São Paulo: Annablume, 2007.

GRINBERG, Luiz Paulo. Jung: o homem criativo. São Paulo: FTD, 1997.

JUNG, Carl Gustav. Os arquétipos e o inconsciente coletivo. $2^{\mathrm{a}}$ edição. Petrópolis: Vozes, 2000. [0C9/1]. 


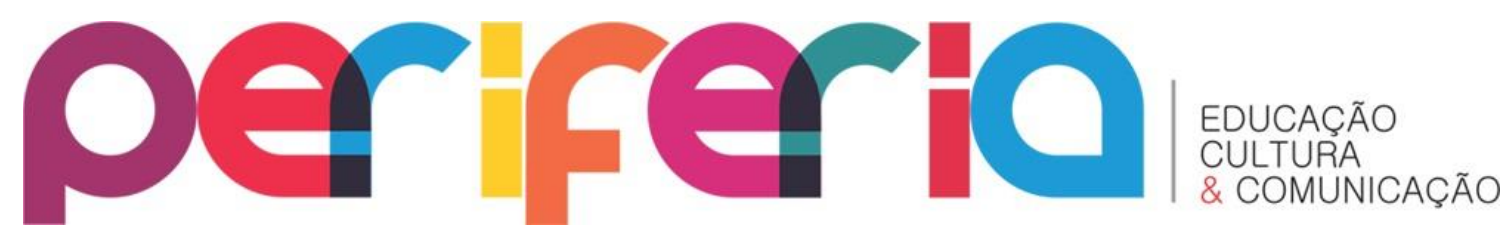

Fronteira, 2008.

O homem e seus símbolos. $2^{\text {a }}$ edição. Rio de Janeiro: Nova . Símbolos da transformação. $8^{\mathrm{a}}$ edição. Petrópolis: Vozes, 2012.

[OC 5].

KÜNSCH, Dimas A. A comunicação, a explicação e a compreensão: ensaio de uma epistemologia compreensiva da comunicação. Líbero, $17, n^{\circ} 34$, jul/dez 2014a, p.111-122.

KÜNSCH, Dimas A. Comunicação e pensamento compreensivo: um breve balanço. In: KÜNSCH, Dimas A.; MARTINO, Luís Mauro Sá (Orgs.).

Comunicação, jornalismo e compreensão. São Paulo: Plêiade, 2010, p. 13-47.

KÜNSCH, Dimas A.; MEDINA, Cremilda. Andança Mágica em outra história: uma conversa sobre a narrativa do mito. In: Comunicação, diálogo e compreensão. Dimas A. Künsch, Guilherme Azevedo, Pedro Debs Brito, Viviane Regina Mansi (Orgs.). São Paulo: Editora Plêiade, 2014b, p. 63-78.

MARTINO, Luís Mauro. A compreensão como método. In: Comunicação, diálogo e compreensão. KÜNSCH, Dimas A., AZEVEDO, Guilherme, BRITO Pedro Debs , MANSI, Viviane Regina (Orgs.). São Paulo: Editora Plêiade, 2014, p.17-36.

MEDINA, Cremilda. A arte de tecer o presente: narrativa e cotidiano. São Paulo: Summus, 2003.

Paulo: Paulus, 2006. O signo da relação: comunicação e pedagogia dos afetos. São - Ciência e jornalismo: da herança positivista ao diálogo dos afetos. São Paulo: Summus, 2008.

MOTTA, L. G. Narrativas: representação, instituição ou experimentação da realidade? VII Encontro Nacional de Pesquisadores em Jornalismo. São Paulo, Universidade de São Paulo, novembro de 2009. Disponível em: <https://www.yumpu.com/pt/document/view/38447078/co-06-luiz-gonzagamotta-sbpjor >. Acesso em: 22 de jun. 2017.

PONTES, Ana. Anjo Azul. Revista Crescer, São Paulo, n² 277, Dezembro/2016, p.56.

SALEH, Naíma. Vidas Inspiradoras. Revista Crescer, São Paulo, n² 277, Dezembro/2016, p.70.

SILVEIRA, Nise da. Jung, vida e obra. Rio de Janeiro: Paz e Terra, 1981. 